\title{
Pulmonary challenge with carbon nanoparticles induces a dose-dependent increase in circulating leukocytes in healthy males
}

Marieke Berger ${ }^{1 *}$ D , Johannes D. de Boer ${ }^{2}$, René Lutter ${ }^{1,3}$, Michiel Makkee ${ }^{4}$, Peter J. Sterk ${ }^{1}$, Elles M. Kemper ${ }^{5}$ and Jaring S. van der Zee $e^{1,6}$

\begin{abstract}
Background: Inhalation of particulate matter, as part of air pollution, is associated with increased morbidity and mortality. Nanoparticles ( $<100 \mathrm{~nm}$ ) are likely candidates for triggering inflammatory responses and activation of coagulation pathways because of their ability to enter lung cells and pass bronchial mucosa. We tested the hypothesis that bronchial segmental instillation of carbon nanoparticles causes inflammation and activation of coagulation pathways in healthy humans in vivo.

Methods: This was an investigator-initiated, randomized controlled, dose-escalation study in 26 healthy males. Participants received saline (control) in one lung segment and saline (placebo) or carbon nanoparticles $10 \mu \mathrm{g}$, $50 \mu \mathrm{g}$, or $100 \mu \mathrm{g}$ in the contra-lateral lung. Six hours later, blood and bronchoalveolar lavage fluid (BALF) was collected for inflammation and coagulation parameters.

Results: There was a significant dose-dependent increase in blood neutrophils $(p=0.046)$ after challenge with carbon nanoparticles. The individual top-dose of $100 \mu \mathrm{g}$ showed a significant $(p=0.05)$ increase in terms of percentage neutrophils in blood as compared to placebo.
\end{abstract}

Conclusions: This study shows a dose-dependent effect of bronchial segmental challenge with carbon nanoparticles on circulating neutrophils of healthy volunteers. This suggests that nanoparticles in the respiratory tract induce systemic inflammation.

Trial registration: Dutch Trial Register no. 2976. 11 July 2011. http://www.trialregister.nl/trialreg/admin/rctview. asp?TC=2976

Keywords: Air pollution, Coagulation, Bronchial provocation test, Bronchoalveolar lavage, Ultrafine particles, Inflammation

\section{Background}

Particulate matter (PM), as part of air pollution, is a complex mixture, consisting of variably sized carbon particles with different types of molecules adsorbed to them. There is a strong association between exposure to particulate matter and increased morbidity and mortality [1-3]. However, it is unclear which components of PM are

\footnotetext{
* Correspondence: m.berger@amc.uva.nl

${ }^{1}$ Department of Respiratory Medicine, Academic Medical Center, University of Amsterdam, Room F-5-260, Amsterdam, The Netherlands

Full list of author information is available at the end of the article
}

responsible for these health effects. Human inhalation studies showed that exposure to particulate matter from air pollution causes pulmonary and systemic inflammation $[4,5]$, as measured by blood neutrophils [6], and Creactive protein, increased thrombogenesis [7] and altered autonomic function, as represented by an increase in blood pressure and heart rate [8].

Nanoparticles, with a diameter of less than $0.1 \mu \mathrm{m}$, are likely candidates for causing the pulmonary and systemic effects associated with particulate matter $[9,10]$, because of their higher oxidant capacity compared to larger 
particles [11], their higher deposition efficiency in the pulmonary region [12], and their ability to penetrate lung cells $[13,14]$. Nanoparticles, while constituting a small fraction of the total mass of ambient particulate matter, represent a major proportion in terms of particle number and surface area [15].

Most human in vivo studies used inhalation challenges with larger particles or complete diesel exhaust, which is composed of different particles with respect to size and arrangement. Although this gives very relevant information about the general health effects of ambient exposures, it still needs to be examined which specific fractions of particulate matter are causatively driving the observed health effects. This is even more important for people exposed to high concentrations of particulate matter on a daily basis due to their occupation, such as tunnel workers or Carbon Black production workers. In order to evaluate the health effects of such extensive, variate exposures, we suggest a systematical, step-by-step approach. Therefore, in the current study we examined the effect of pure, graphitic, onion-like, carbon nanoparticles, and the core fraction of ambient particulate matter, on local (lung) and systemic inflammation and activation of coagulation in human beings.

Previous human in vivo studies focusing on nanoparticles have examined translocation to the systemic circulation [16], and vascular function [17] after whole lung inhalation. In addition, nanotoxicity in experimental animals and in vitro studies appears to be related to several cellular mechanisms, including oxidative stress formation $[5,18]$, and increase of cytosolic calcium concentration in platelets [19]].

We hypothesized that carbon nanoparticles cause dosedependent local and systemic activation of inflammatory and coagulation pathways after pulmonary instillation. The aim of the study was to test this hypothesis in humans in vivo by using the well-established method of bronchial segmental challenge $[20,21]$ in order to avoid serious adverse events.

\section{Methods}

\section{Subjects}

Twenty-six healthy, non-smoking males between 18 and 45 years of age were recruited by advertising. Subjects were included if there were no significant findings during screening, consisting of a medical history, physical examination, lung function measurement $\left(\mathrm{FEV}_{1}\right)$ [22], and hematological and biochemical screening. Volunteers were excluded when having a history of pulmonary disease, enhanced bleeding tendency, or smoking within the past 12 months and more than 5 pack years of smoking history. We continued recruitment until 26 subjects completed all visits, yielding sufficient material for analysis. All volunteers gave written informed consent and the institutional Ethics Committee approved the study (Dutch Trial Register no. 2976. http://www.trialregister.nl/trialreg/admin/rctview.asp?TC=2976).

\section{Study design}

This was an investigator initiated, randomized controlled, single-center, single-blinded dose-escalation study. In order to ensure the safety of the study participants, doseescalation was performed according to the European Medicines Agency (EMA) First-In-Man (FIM) guidelines [23]. Escalating dosages of $10 \mu \mathrm{g}, 50 \mu \mathrm{g}$, and $100 \mu \mathrm{g}$ of carbon nanoparticles were instilled, by using different groups of volunteers per dose (Fig. 1). Dosages were aimed to be in line with real life exposure concentrations. They were calculated according to the European Medicines Agency (EMA) First-In-Man (FIM) guidelines [23]. Based on the No Observed Adverse Effect Level (NOAEL) in nonclinical safety studies, safe dosages for human use were calculated by adjustment for allometric factors (body volume, surface area). These dosages are identical to measured concentrations at various locations in the Netherlands by Strak et al. [24]. These locations comprised an underground train station and several traffic sites. As this was the first study investigating segmental instillation of the lung with carbon particles, a very low starting dose of $10 \mu \mathrm{g}$ was chosen. To guarantee the safety of study participants a data safety monitoring board (DSMB) was appointed and after completion of each dose, an interim analysis was performed by this board regarding adverse events, symptoms and white blood cell count in bronchoalveolar lavage fluid.

If any adverse event occurred, the previous dose would be regarded as maximum tolerable dose (MTD), and this dosage group would be completed up to 9 volunteers. Also, if there would be a mean difference of $50 \%$ or more in BAL leukocytes (control versus challenge lung), this dosage was to be regarded as minimum effective dose (MED) for this model and this group was to be completed up to 9 volunteers.

\section{Study day}

Healthy males were randomized (by envelopes) to receive bronchial segmental challenge with placebo $(20 \mathrm{ml}$ sodium chloride $0.9 \%$ ) or a suspension of carbon nanoparticles in saline $(20 \mathrm{ml}$ sodium chloride $0.9 \%)$ in a subsegment of the lingula or right middle lobe. This was performed after control challenge (sodium chloride $0.9 \%$ ) in the contralateral lung subsegment. Six hours later, a second bronchoscopy with bronchoalveolar lavage (8 times $20 \mathrm{ml}$ ) of the challenged segment (nanoparticles or saline) and the saline challenged control segment was performed according to the BTS-guidelines [25]. Both bronchoscopies were preceded by lung function test $\left(\mathrm{FEV}_{1}\right)$ and blood draw, while vital signs were measured regularly during the study day. 


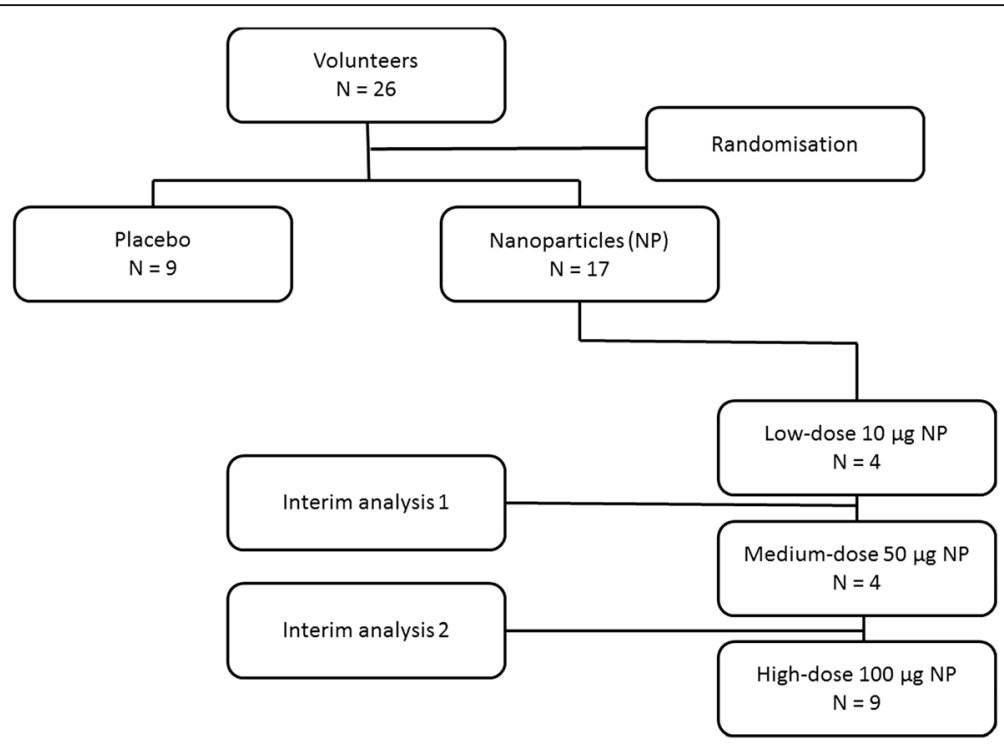

Fig. 1 Flow-chart study design

\section{Materials}

Carbon nanoparticles (Printex-U) were purchased from Evonik Carbon Black GmbH, Hanau, Germany. The properties of the particles (raw material) and the final product (particles suspended in saline) were thoroughly analyzed for size distribution, arrangement (onion-like), $\mathrm{pH}$, purity (no surface group), contamination with endotoxins, and stability by transmission electron microscopy (TEM), element analysis, and nanoparticle tracking analysis. Analyses were performed by experienced scientists of the Technical University Delft, the Netherlands. This information was registered in a Product Dossier (See Additional file 1), which was presented to the Ethics Committee for assessment prior to the start of the study [26].

For each study participant a fresh suspension (within $12 \mathrm{~h}$ of administration) was prepared in a laminar flow cabinet. The carbon powder was accurately weighed and mixed with pulverized sodium chloride by serial dilution technique. A precisely weighed amount of this mixture was suspended in water for injections and the final suspension was sterilized in a validated autoclave $\left(121{ }^{\circ} \mathrm{C}\right.$, $15 \mathrm{~min})$. Endotoxin concentration of the nanoparticle suspension was $<0.01 \mathrm{EU} / \mathrm{ml}$. Before bronchial segmental challenge the nanoparticle suspension was sonicated for $5 \mathrm{~min}$ in a table water sonicator.

\section{Measurements}

Spirometry (MasterscreenPneumo; Jaeger; Würzburg, Germany) was performed according to the guidelines of the European Respiratory Society (ERS) [22] and hematological and biochemical analyses on peripheral blood were done in a standardized way by the institutional laboratory of clinical chemistry.
Blood samples were drawn in standard tubes with heparin, EDTA, and citrate. To inhibit proteolytic activity and degradation of complement products we used stabilyte tubes with benzamine $\left(\right.$ BioPool $^{\oplus}$ Stabilyte $^{\mathrm{Tm}}$ ). They were centrifuged at $8^{\circ} \mathrm{C}$ and $3000 \mathrm{rpm}$ for $10 \mathrm{~min}$ in a table centrifuge. Supernatant was stored at $-80^{\circ} \mathrm{C}$. BALF fractions 2-8 were pooled (per lung segment) and centrifuged at $8{ }^{\circ} \mathrm{C}$ and $1240 \mathrm{rpm}$ for $10 \mathrm{~min}$. Before centrifugation, benzamidine was added to a separate aliquot of BALF. Supernatants were stored at $-80^{\circ}$ Celcius until we analyzed them in parallel to reduce inter-assay variation. For coagulation measurements, citrate plasma and BALF samples were snap frozen in liquid nitrogen before storage.

In peripheral blood we measured leukocyte cell counts $\left(\times 10^{9} / \mathrm{L}\right)$, Cell differentials $\left(\times 10^{9} / \mathrm{L}\right)$, C-reactive protein $(\mathrm{CRP})$ in $\mathrm{mg} / \mathrm{L}$, von Willebrand Factor in \% (Elisa, Homemade), Plasmin-Anti-Plasmin (PAP) in $\mu \mathrm{g} / \mathrm{L}$ (Elisa, DRG Diagnostica), D-dimer in mg/L FEU (BCS-XP, Siemens), Endogenous Thrombin Potential (ETP) in \% (Calibrated Automated Thrombogram), and TAT complexes in $\mu \mathrm{g} / \mathrm{L}$ (Elisa, Siemens, Marburg, Germany).

Cell differentials of 500 cells from BALF were performed on cytospins stained with a modified Giemsa stain (DiffQuick; Dade Behring AG, Düdingen, Switzerland). Cell concentrations were calculated as (\% cells $\mathrm{x}$ total cell count)/volume in BALF.

Next to this, we measured local inflammatory cytokines and chemokines in BALF. This comprised Eosinophil Cationic Protein (ECP) and Myeloperoxidase (MPO) by ELISA (Diagnostics Development and Duoset DY3174 R\&D, respectively). Interleukin (IL) 6, IL-8, IL-10, IL-17A, IP-10, GRO- $\alpha$, MCP-1, MIP-1 $\alpha$, MIP-1 $\beta$, Tumor Necrosis Factor alpha (TNF- $\alpha)$, and Vascular Endothelial Growth Factor 
(VEGF) were determined by multiplex bead flow assays (BioRad) and read on a Bioplex 200 reader (Bio-Rad Laboratories, Inc., Hercules, CA). Concerning coagulation parameters, we measured D-dimer (Elisa, Stago Diagnostica), Plasminogen-Activator-Inhibitor-Antigen (PAI-Ag) (Elisa, BioMed), and TAT complexes (Elisa, Siemens, Marburg, Germany). All measurements were performed by experienced and qualified technicians who were blinded to the clinical details.

In order to determine the quality of assay performance, we calculated the inter-assay coefficients of variation $(\mathrm{CV})$. For the primary outcome parameters (white blood cell counts), the inter-assay CV's for total leucocytes, neutrophils, lymphocytes and eosinophils are $1,9 \%, 2,5 \%, 3,7 \%$ and $9,2 \%$ respectively.

Concerning the secondary outcome parameters, only ECP and MPO were analyzed by ELISA. The inter-assay CV's were $13 \%$ and $14 \%$ respectively.

Other secondary outcomes were analyzed by multiplex bead flow assays. For these assays, we checked with the controls to determine whether the cytokines were properly measured and the software calculated the upper and lower limit of quantification (ULOQ and LLOQ).

\section{Statistical analysis}

The primary endpoint was total leukocyte cell count and differentials in peripheral blood and BALF, while secondary endpoints comprised safety parameters and other markers of inflammation and coagulation activation in peripheral blood and BALF including activation of cytokine/chemokine networks, complement activation, and activation of the protein $\mathrm{C}$ system.

Based on previous studies with LPS challenge using the same research protocol $(20 ; 28)$ a sample size of 18 (placebo versus highest dosage nanoparticles) was estimated to have a power of $80 \%$ to detect a $50 \%$ difference in BALF leukocytes between placebo (saline) and nanoparticle challenged lung segments. $P$-values less than 0.05 were considered significant.

For the dose-response evaluation of blood parameters we performed non-parametric Spearman correlation test of the dose versus the change in blood values before challenge and $6 \mathrm{~h}$ after challenge.

We analyzed blood and BALF parameters of the placebo group and the subjects who received the top dose of $100 \mu \mathrm{g}$ nanoparticles with non-parametric Mann-Whitney test. All analyses were performed with SPSS 20 for Windows.

\section{Results}

Subject characteristics were not significantly different between groups $(p>0.05$, Table 1$)$. From 26 screened and randomized participants, one did not complete the second bronchoscopy due to medical reasons (unrelated to the study). We were able to collect blood samples before and $6 \mathrm{~h}$ after provocation from 26 patients. Analysis of BALF and coagulation parameters in blood was performed in 25 subjects.

\section{Safety analysis}

Interim analysis, as assessed by the DSMB, after completion of each dose-group showed no significant adverse events, symptoms, or doubling of white blood cell counts. There was one participant, who received $10 \mu \mathrm{g}$ carbon nanoparticles, who had complaints of fever and chest pain after the study day. He showed no signs of pneumonia, pneumothorax or pulmonary embolism. The subject was treated with analgesics for one day, after which the complaints disappeared.

\section{Inflammation parameters: Dose-response correlations}

There was a significant dose-dependent increase in blood neutrophils (Spearman $p=0.0468$ ) and a trend towards increased blood leukocytes $(p=0.061)$ after challenge with carbon nanoparticles as compared to placebo. Figure 2 shows the means of circulating neutrophils before and $6 \mathrm{~h}$ after bronchial segmental challenge with placebo, $10 \mu \mathrm{g}, 50 \mu \mathrm{g}$, and $100 \mu \mathrm{g}$ carbon nanoparticles. In Table 2 the means of circulating leukocytes and neutrophils are shown after segmental challenge. In BALF there were no significant differences measured between the different dosage groups. Additionally, we compared the results of the different groups with each other. Additional file 2: Table S1 shows the analysis of the inflammation parameters after challenge with placebo as compared to $10 \mu \mathrm{g}$ nanoparticles in blood and BALF. In Table S2 of the Additional file 2 the results of the comparison between placebo and $50 \mu \mathrm{g}$ nanoparticles is shown. Results of the analysis between $10 \mu \mathrm{g}$ nanoparticles and $50 \mu \mathrm{g}$ nanoparticles are described in Additional file 2: Table S3. Comparison of $10 \mu \mathrm{g}$ nanoparticles versus $100 \mu \mathrm{g}$ nanoparticles is shown in Additional file 2: Table S4. Analysis of $50 \mu \mathrm{g}$ nanoparticles as compared to the $100 \mu \mathrm{g}$ nanoparticle group is presented in Table S5 of the Additional file 2.

\section{Inflammation parameters: Placebo versus $100 \mu \mathrm{g}$ Nanoparticles (non-parametric analysis, table 3)}

Segmental challenge with the individual top-dose of $100 \mu \mathrm{g}$ carbon nanoparticles showed a significant relative increase of neutrophils $(p=0.05)$ in peripheral blood as compared to placebo (See Table 3). No other significant differences in circulating inflammation parameters were observed between these groups.

Data on the analysis between the different dosage groups is presented in the Additional file 2. Measurements of monocytes, mast cells, plasma cells, and IL-17A were below the detection limit. 
Table 1 Baseline characteristics

\begin{tabular}{|c|c|c|c|c|c|}
\hline & Placebo $(n=9)$ & $10 \mu \mathrm{gNP}(n=4)$ & $50 \mu \mathrm{g} \mathrm{NP}(n=4)$ & $100 \mu \mathrm{g} \mathrm{NP}(n=9)$ & $P$-value \\
\hline$\overline{\text { Age, } \text { Year }^{\mathrm{a}}}$ & $26.0(22-30)$ & $26.0(26-27)$ & $21.5(20-31)$ & $24.0(19-35)$ & 0.70 \\
\hline $\mathrm{FEV}_{1}$, Liter $^{\mathrm{b}}$ & $4.92(0.70)$ & $5.23(1.19)$ & $4.55(0.37)$ & $5.05(0.95)$ & 0.78 \\
\hline Blood leukocytes, Cells $\times 10^{9} / \mathrm{L}^{\mathrm{b}}$ & $5.43(1.16)$ & $5.70(0.52)$ & $5.10(0.62)$ & $5.70(1.60)$ & 0.85 \\
\hline
\end{tabular}

Values are expressed as a Median (Range), ${ }^{\mathrm{b}}$ Mean $\pm \mathrm{SD}$, and analyzed by One-Way ANOVA. Abbreviations: NP nanoparticles, FEV ${ }_{1}$ forced expiratory volume in $1 \mathrm{~s}$

\section{Coagulation parameters: Placebo versus $100 \mu \mathrm{g}$ Nanoparticles (Non-parametric analysis)}

Comparison of coagulation parameters after bronchial segmental challenge with saline (placebo) or $100 \mu \mathrm{g}$ nanoparticles showed no significant differences between those groups. Table 4 summarizes the coagulation parameters in blood and BALF after bronchial segmental challenge with placebo or $100 \mu \mathrm{g}$ carbon nanoparticles.

\section{Discussion}

This study shows that bronchial segmental challenge with carbon nanoparticles up to a maximum of $100 \mu \mathrm{g}$ is safe, and causes a significant dose-dependent increase in circulating neutrophils and a trend towards increased leukocytes. In the subgroup of patients challenged with $100 \mu \mathrm{g}$ nanoparticles, there was a significant relative increase of neutrophils in peripheral blood as compared to placebo (non-parametric analysis by Mann Whitney test). These results suggest the activation of an acute phase response after challenge with carbon nanoparticles.

To our knowledge, this is the first study investigating the effect of bronchial segmental challenge with carbon nanoparticles on local and systemic inflammation and coagulation. The study is the first part of a stepwise approach, examining which characteristics and constituents of air pollution can be responsible for the observed health effects. We observed a significant dose-dependent effect on circulating neutrophils. This seems to be in line with previous studies investigating human inhalation of diesel exhaust, air pollution, and nanoparticles [6, 27, 28], who showed a significant increase in circulating cells and interleukins. Interestingly, Frampton and colleagues [28], showed a reduced expression of adhesion molecules on blood leukocytes after inhalation of generated ultrafine elemental carbon particles during exercise. This might be caused by an effect of nanoparticles on the pulmonary vasculature. Concerning coagulation parameters, we found no differences between placebo and $100 \mu \mathrm{g}$ nanoparticle challenge. This is in contrast with Viehmann et al. [7], who found associations between long-term exposure to fine particulate matter and increased high-sensitivity $\mathrm{C}$ reactive protein and platelets.

Taken together, our data extend previous observations of inflammation into the nanoparticle range.

Blood neutrophils before and 6 hours after challenge with placebo, $10 \mu \mathrm{g}, 50 \mu \mathrm{g}$, or 100

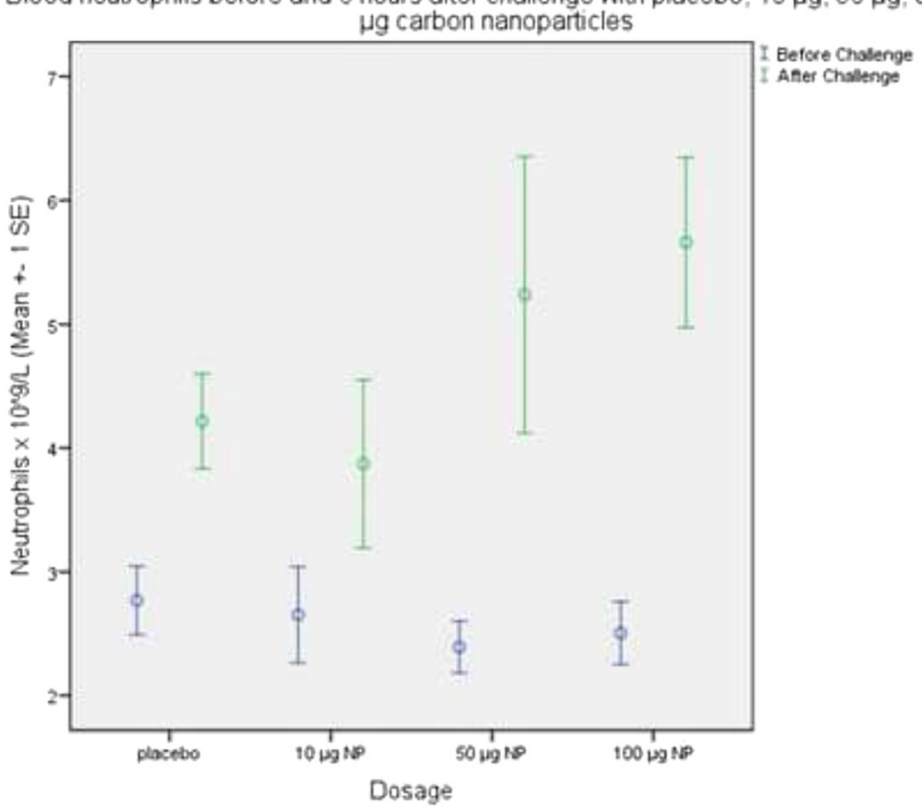

Fig. 2 Peripheral blood neutrophils before (black bars) and $6 \mathrm{~h}$ after (green bars) bronchial segmental challenge with placebo, $10 \mu \mathrm{g}, 50 \mu \mathrm{g}$, or $100 \mu \mathrm{g}$ carbon nanoparticles (NP). Values are expressed as mean \pm 1 Standard Error 
Table 2 Inflammation parameters in blood $6 \mathrm{~h}$ after bronchial segmental challenge with placebo, $10 \mu \mathrm{g}, 50 \mu \mathrm{g}$, or $100 \mu \mathrm{g}$ carbon nanoparticles

\begin{tabular}{|c|c|c|c|c|c|}
\hline Peripheral Blood Cells $\times 10^{9} / \mathrm{L}$ & Placebo $(n=9)$ & $10 \mu \mathrm{g} \mathrm{NP}(n=4)$ & $50 \mu \mathrm{g} \mathrm{NP}(n=4)$ & $100 \mu \mathrm{g} \mathrm{NP}(n=9)$ & $P$-value \\
\hline Leukocytes & $6.61 \pm 0.38$ & $6.10 \pm 0.45$ & $7.65 \pm 1.13$ & $8.24 \pm 0.77$ & 0.061 \\
\hline Neutrophils & $4.22 \pm 0.38$ & $3.87 \pm 0.68$ & $5.24 \pm 1.12$ & $5.66 \pm 0.69$ & 0.046 \\
\hline Lymphocytes & $1.76 \pm 0.11$ & $1.64 \pm 0.28$ & $1.78 \pm 0.17$ & $1.89 \pm 0.11$ & 0.934 \\
\hline Monocytes & $0.49 \pm 0.03$ & $0.48 \pm 0.04$ & $0.55 \pm 0.08$ & $0.57 \pm 0.06$ & 0.156 \\
\hline Eosinophils & $0.13 \pm 0.03$ & $0.07 \pm 0.03$ & $0.07 \pm 0.03$ & $0.10 \pm 0.04$ & 0.602 \\
\hline Basophils & $0.03 \pm 0.01$ & $0.04 \pm 0.01$ & $0.03 \pm 0.01$ & $0.02 \pm 0.00$ & 0.970 \\
\hline
\end{tabular}

Values are expressed as mean $\pm \mathrm{SEM}$. The correlations between dose of nanoparticles and changes from baseline of cell numbers were non-parametrically analyzed by Spearman correlation. Abbreviations: NP nanoparticles

Table 3 Inflammation parameters in blood and BALF 6 h after bronchial segmental challenge with placebo or 100 Mg nanoparticles

\begin{tabular}{|c|c|c|c|}
\hline $\begin{array}{l}\text { Inflammation Parameters } \\
\text { Blood }\end{array}$ & $\begin{array}{l}\text { Placebo } \\
N=9\end{array}$ & $\begin{array}{l}100 \mu \mathrm{g} \mathrm{NP} \\
N=9\end{array}$ & $P$-value \\
\hline Leukocytes, Cells $\times 10^{9} / \mathrm{L}$ & $6.60(4.8-8.5)$ & $8.70(5.6-12.4)$ & 0.161 \\
\hline Neutrophils, Cells $\times 10^{9} / \mathrm{L}$ & $4.35(2.9-6.6)$ & $6.15(3.4-9.7)$ & 0.050 \\
\hline Lymphocytes, Cells $\times 10^{9} / \mathrm{L}$ & $1.76(1.4-2.3)$ & $1.77(1.5-2.5)$ & 0.931 \\
\hline Monocytes, Cells $\times 10^{9} / \mathrm{L}$ & $0.52(0.3-0.6)$ & $0.59(0.3-0.9)$ & 0.387 \\
\hline Eosinophils, Cells $\times 10^{9} / \mathrm{L}$ & $0.11(0.1-0.3)$ & $0.07(0.0-0.4)$ & 0.931 \\
\hline Basophils, Cells $\times 10^{9} / \mathrm{L}$ & $0.03(0.0-0.1)$ & $0.02(0.0-0.1)$ & 0.931 \\
\hline$C R P, m g / L$ & $0.50(0.3-7.4)$ & $0.40(0.3-3.5)$ & 1.000 \\
\hline $\begin{array}{c}\text { Inflammation Parameters } \\
\text { BALF }\end{array}$ & $\begin{array}{l}\text { Placebo } \\
N=8\end{array}$ & $\begin{array}{c}100 \mu \mathrm{g} \mathrm{NP} \\
\quad N=9\end{array}$ & $P$-value \\
\hline Leukocytes, Cells $\times 10^{4} / \mathrm{ml}$ & $9.47(6.5-36.5)$ & $11.63(5.7-18.7)$ & 1.000 \\
\hline Neutrophils, Cells $\times 10^{4} / \mathrm{ml}$ & $0.33(0.1-2.6)$ & $0.58(0.1-3.8)$ & 0.637 \\
\hline Lymphocytes, Cells $\times 10^{4} / \mathrm{ml}$ & $0.31(0.1-0.7)$ & $0.40(0.1-1.6)$ & 0.153 \\
\hline Monocytes, Cells $\times 10^{4} / \mathrm{ml}$ & - & - & 1.000 \\
\hline Eosinophils, Cells $\times 10^{4} / \mathrm{ml}$ & $0.03(0.0-0.3)$ & $0.00(0.0-0.1)$ & 0.637 \\
\hline Macrophages, Cells $\times 10^{4} / \mathrm{ml}$ & $8.72(6.0-33.1)$ & $9.04(5.0-16.9)$ & 0.347 \\
\hline Mast cells, Cells $\times 10^{4} / \mathrm{ml}$ & $0.00(0.0-0.0)$ & $0.00(0.0-0.0)$ & - \\
\hline Plasma cells, Cells $\times 10^{4} / \mathrm{ml}$ & - & - & - \\
\hline $\mathrm{ECP}, \mathrm{ng} / \mathrm{ml}$ & $0.65(0.3-2.3)$ & $0.76(0.1-1.9)$ & 0.347 \\
\hline $\mathrm{MPO}, \mathrm{ng} / \mathrm{ml}$ & $13.91(5.1-43.3)$ & $14.28(6.3-35.7)$ & 1.000 \\
\hline GRO-a, ng/ml & $0.60(0.3-0.9)$ & $0.49(0.2-1.5)$ & 1.000 \\
\hline IL-6, pg/ml & $5.39(1.0-57.0)$ & $25.57(0.2-124.0)$ & 1.000 \\
\hline $\mid \mathrm{L}-8, \mathrm{ng} / \mathrm{ml}$ & $0.03(0.0-0.5)$ & $0.13(0.0-2.2)$ & 1.000 \\
\hline IL-17, pg/ml & $1.60(1.6-1.6)$ & $1.60(1.6-1.6)$ & - \\
\hline CXCL-10, ng/ml & $0.66(0.1-5.6)$ & $1.02(0.1-5.3)$ & 1.000 \\
\hline MCP-1, ng/ml & $0.02(0.0-0.1)$ & $0.02(0.0-0.8)$ & 1.000 \\
\hline MIP-1a, pg/ml & $0.15(0.2-8.5)$ & $3.76(0.2-31.1)$ & 1.000 \\
\hline $\mathrm{MIP}-1 \beta, \mathrm{ng} / \mathrm{ml}$ & $0.06(0.0-1.0)$ & $0.48(0.0-7.1)$ & 1.000 \\
\hline TNF-a, pg/ml & $0.60(0.6-1.5)$ & $1.15(0.6-15.1)$ & 0.576 \\
\hline VEGF, ng/ml & $0.78(0.0-1.7)$ & $0.51(0.2-1.7)$ & 0.057 \\
\hline
\end{tabular}

Values are expressed as median (minimum -maximum values). Changes in blood values (pre-challenge baseline and $6 \mathrm{~h}$ post-challenge) and BALF values (control segment and challenged segment $6 \mathrm{~h}$ after challenge) were non-parametrically analyzed by Mann-Whitney test

Abbreviations: NP nanoparticles, CRP C-reactive protein, ECP Eosinophil Cationic Protein, MPO Myeloperoxidase, GRO- $a$ Growth Regulated Oncogene-alpha, IL Interleukin, CXCL10 Interferon gamma-induced protein 10, MCP-1 Monocyte Chemoattractant Protein 1, MIP-1a Macrophage Inflammatory Protein 1 alpha, MIP-1 $\beta$ Macrophage Inflammatory Protein 1 beta, TNF- $a$ Tumor Necrosis Factor alpha, VEGF Vascular Endothelial Growth Factor 
Table 4 Coagulation parameters in blood and BALF $6 \mathrm{~h}$ after bronchial segmental challenge with placebo or $100 \mu \mathrm{g}$ nanoparticles

\begin{tabular}{|c|c|c|c|}
\hline $\begin{array}{l}\text { Coagulation Parameters } \\
\text { In Blood }\end{array}$ & $\begin{array}{l}\text { Placebo } \\
N=8\end{array}$ & $\begin{array}{l}100 \mu \mathrm{g} \mathrm{NP} \\
N=9\end{array}$ & $P$-value \\
\hline vWF, In percentage & $80.50(19.0-149.0)$ & 95.00 (53.0-115.0) & 1.000 \\
\hline TATc, in $\mu \mathrm{g} / \mathrm{L}$ & $2.85(2.3-26.6)$ & $2.70(2.3-3.3)$ & 0.347 \\
\hline D-dimer, in mg/L FEU & $0.17(0.2-0.2)$ & $0.17(0.2-0.2)$ & 1.000 \\
\hline PAP, In mg/L & $0.68(0.3-1.4)$ & $0.46(0.4-0.6)$ & 0.347 \\
\hline ETP, in percentage & $93.00(85.0-117.0)$ & 98.00 (79.0-103.0) & 1.000 \\
\hline $\begin{array}{l}\text { Coagulation parameters } \\
\text { in BALF }\end{array}$ & $\begin{array}{c}\text { Placebo } \\
N=8\end{array}$ & $\begin{array}{c}100 \mu \mathrm{g} \mathrm{NP} \\
\quad N=9\end{array}$ & $P$-value \\
\hline TATc, in $\mu \mathrm{g} / \mathrm{L}$ & $2.85(1.1-10.9)$ & $2.80(0.1-8.8)$ & 0.347 \\
\hline D-dimer, in $\mu \mathrm{g} / \mathrm{L}$ & $7.00(2.0-17.0)$ & $5.00(1.0-29.0)$ & 0.050 \\
\hline PAl-Ag, in $n g / m L$ & $0.50(-0.5-0.5)$ & $0.50(0.5-0.5)$ & - \\
\hline
\end{tabular}

Values are expressed as median (minimum - maximum values). Changes in blood values (pre-challenge baseline and $6 \mathrm{~h}$ post-challenge) and BALF values (control segment and challenged segment $6 \mathrm{~h}$ after challenge) were non parametrically analyzed by Mann-Whitney test

Abbreviations: NP nanoparticles, vWF von Willebrand Factor, TATC Thrombin AntiThrombin Complex, PAP Plasmin-Anti-Plasmin, ETP Endogenous Thrombin Potential, PAI-Ag Plasminogen-Activator-Inhibitor-Antigen

We believe that bronchial segmental challenge can be regarded as a strength of the present study. Previous investigators showed that it is a safe, and well-tolerated technique [20,21,29], in which a limited amount of lung tissue is exposed to the challenging agent, reducing the risk of bronchoconstriction or an allergic reaction. Another advantage for measuring local effects by this research model is that a placebo challenge in a subsegment of the contra-lateral lung can be used as a control during the same experiment in the same subject. Therefore, we were able to reduce the amount of participants. In spite of the safety and advantages of this research model, there are still risks related to the procedure of bronchoscopy. For instance, it could be possible that segmental instillation causes local airway injury due to the relatively high concentration of particles to a small surface area. In this study, we only observed small differences between placebo and nanoparticle challenges. Therefore, we think that the possible local airway injury at the site of instillation is caused by instillation in general and not dependent of the amount of nanoparticles in the suspension. Nevertheless, we should emphasize that real life exposure is by inhalation and not by instillation.

In order to increase safety, we used a dose-escalation design, and small dosages of nanoparticles similar to real life exposures in the Netherlands, as observed by Strak et al. [24]. The dosages were also comparable with several animal studies [30, 31]. Next to this, we selected neutral, apolar, spherical, and pure carbon nanoparticles which resemble the carbon particles in air pollution concerning particle characteristics. Finally, we performed an extensive characterization of the carbon nanoparticles by building a Product Dossier (See Additional file 1) [26].

Nevertheless, the current study also has a few limitations. We tried to prevent the particles from clustering by ultrasonification. Although the majority of particles were representing separate nanoparticles as shown by transmission electron microscopy (TEM), we could not avoid the presence of some larger agglomerates in the final nanoparticle suspension in saline. This contrasts to Creutzenberg et al., who showed no change in diameter of carbon black agglomerates after instillation in rats [30].

Secondly, we powered on local and systemic inflammation parameters, using blood and BALF leukocyte counts as primary outcome. Nevertheless, considering our results, which show a significant effect on circulating neutrophils in the subgroup challenged with $100 \mu \mathrm{g}$ nanoparticles, we cannot exclude that the study is underpowered with respect to the individual top-dose of $100 \mu \mathrm{g}$ nanoparticles.

Furthermore, the time-frame of our study, in which we collected the blood and BALF $6 \mathrm{~h}$ after the provocation, covers the early phase of the inflammatory response. We may have missed possible effects of carbon nanoparticles on inflammation or coagulation within these $6 \mathrm{~h}$ or later. As shown by Gardner et al. [32], the increased risk of myocardial infarction after exposure to elevated concentrations of air pollution varies from one hour up to a few days. Also, we performed the challenges in healthy males and we don't know whether the results can be extrapolated to females.

The underlying mechanisms of how carbon nanoparticles can induce the systemic increase in neutrophils is as yet unknown. Saber and colleagues [15], propose that nanoparticles induce a strong pulmonary acute phase response in which $\mathrm{Saa} 3$ is upregulated, causing neutrophil influx into the lungs. Whereas Franklin et al. [8] hypothesize that spillover of inflammatory mediators and cells from the lungs into the systemic circulation causes the systemic effects of inhalation of nanoparticles, our data do not favor the latter explanation, as we 
observed only limited local inflammatory responses to nanoparticles in BALF.

Animal and in vitro models have also shown that nanoparticle inhalation or instillation can induce an acute inflammatory response [33]. Observed mechanisms concern oxidative stress $[5,18]$, epithelial damage [34], polarization of Th17 leading to enhanced differentiation [35], and an increase of cytosolic calcium concentration in platelets [19]. However, these effects are not specific for carbon nanoparticles.

We observed no significant changes in coagulation related parameters. This is in line with previous human inhalation studies which showed inconclusive results concerning the thrombotic tendency of diesel exhaust as measured by CRP, von Willebrand Factor, PAI-1, and platelets $[15,36]$.

Notably, our data show an increase in circulating neutrophils after challenge with low dose, pure, and clean carbon nanoparticles. C-reactive protein was not increased $6 \mathrm{~h}$ after challenge, probably due to a more delayed response time as compared to circulating neutrophils. These findings seem to be relevant, since increased circulating inflammatory parameters, such white blood cell count (WBC), neutrophils and CRP are associated with an increased cardiovascular risk, and a higher mortality $[15,37,38]$.

It should be emphasized that the present study was done in healthy volunteers. We think it is not unlikely that more susceptible subjects with pre-existing morbidity, such as asthma [39], COPD, cystic fibrosis [40], or vascular disease, are experiencing more intense acute biological effects after exposure to carbon nanoparticles. In addition, it should be noted that the present study merely addressed acute effects of shortterm carbon nanoparticle exposure. Therefore, it cannot be excluded that long-term, repeated exposures in real-life situations, such as experienced by tunnel workers and industrial workers [41], can have more impact on inflammatory and coagulant pathways. Finally, it is likely that other parts of particulate matter, such as oxidized particles are at least in part responsible for the health effects described. The present data warrant further studies to address these issues.

\section{Conclusions}

In conclusion, we showed that bronchial segmental instillation of pure, apolar, and neutral carbon nanoparticles, is a safe and effective research model. We observed a small, dose-dependent increase in blood leukocytes and blood neutrophils after we challenged healthy males with low dosages of carbon nanoparticles as compared to the daily exposure concentration of certain occupational groups. These results may point towards a pathophysiologic background for the observed health risks associated with increases in air pollution, and merit the next research steps to identify the causative agents.

\section{Additional files}

Additional file 1: Product Dossier. Carbon black nanoparticles (Printex-U). (DOC $3786 \mathrm{~kb}$ )

Additional file 2: Table S1. Inflammation parameters in blood and BALF after challenge with placebo or $10 \mu \mathrm{g}$ nanoparticles. Values are expressed as median with minimum and maximums values. Analysis was performed with non-parametric Mann - Whitney test, after correction for baseline values. Definition of abbreviations: NP: nanoparticles, CRP: Creactive protein. Table S2. Inflammation parameters in blood and BALF after challenge with placebo or $50 \mu \mathrm{g}$ nanoparticles. Values are expressed as median with minimum and maximum values. Analysis was performed with non-parametric Mann - Whitney test, after correction for baseline values. Definition of abbreviations: NP: nanoparticles, CRP: C-reactive protein. Table S3. Inflammation parameters in blood and BALF after challenge with $10 \mu \mathrm{g}$ or $50 \mu \mathrm{g}$ nanoparticles. Values are expressed as median with minimum and maximum values. Analysis was performed with non-parametric Mann Whitney test, after correction for baseline values. Definition of abbreviations: NP: nanoparticles, CRP: C-reactive protein. Table S4. Inflammation parameters in blood and BALF after challenge with $10 \mu \mathrm{g}$ or $100 \mu \mathrm{g}$ nanoparticles. Values are expressed as median with minimum and maximum values. Analysis was performed with non-parametric Mann - Whitney test, after correction for baseline values. Definition of abbreviations: NP: nanoparticles, CRP: C-reactive protein. Table S5. Inflammation parameters in blood and BALF after challenge with $50 \mu \mathrm{g}$ or $100 \mu \mathrm{g}$ nanoparticles. Values are expressed as median with minimum and maximum values. Analysis was performed with non-parametric Mann - Whitney test, after correction for baseline values. Definition of abbreviations: NP: nanoparticles, CRP: C-reactive protein. (DOC 193 kb)

\section{Abbreviations}

ANOVA: ANalysis Of VAriance; ATS: American Thoracic Society; BAL(F): BronchoAlveolar Lavage (Fluid); CRP: C-reactive protein; CXCL10: Interferon gamma-induced protein 10; DSMB: Data safety monitoring board; ECP: Eosinophil Cationic Protein; EMA: European Medicines Agency; ERS: European Respiratory Society; ETP: Endogenous Thrombin Potential; FEV F $_{1}$ Forced expiratory volume in $1 \mathrm{~s}$; FIM: First-In-Man; GINA: Global INitiative for Asthma; GRO-a: Growth Regulated Oncogenealpha; IL: Interleukin; MCP-1: Monocyte Chemoattractant Protein 1; MIP1a: Macrophage Inflammatory Protein 1 alpha; MIP-1ß: Macrophage Inflammatory Protein 1 beta; MPO: Myeloperoxidase; NOAEL: No Observed Adverse Effect Level; PAl-Ag: Plasminogen-Activator-Inhibitor-Antigen; PAP: Plasmin-Anti-Plasmin; PM: Particulate matter; TAT: ThrombinAntiThrombin; TNF-a: Tumor Necrosis Factor alpha; VEGF: Vascular Endothelial Growth Factor; WBC: White blood cell count

\section{Acknowledgements}

The authors gratefully acknowledge the volunteers for their time and effort. Prof. P.J. Kooyman for her TEM measurements, B.S. Smids-Dierdorp, BSC, A. Dijkhuis, BSc, and T. Dekker, BSc for their laboratory assistance, C.J. Majoor, MD, PhD, R van Steenwijk, MD, PhD and L.S. Venekamp, MD, MSc for their assistance performing the bronchoscopies. Substantial appreciation goes to Prof. Dr. Ir. D.J.J. Heederik, R.E. Jonkers, MD, PhD and P. Bresser, MD, PhD for taking place in our Data Safety Monitoring Board.

\section{Funding}

This study was financially supported by the investigators profit from previous studies.

\section{Availability of data and materials}

The datasets analyzed for the current study are available from the corresponding author on reasonable request. 


\section{Authors' contributions}

MB conceived of the study, participated in its design, collected the data, performed statistical analysis, and drafted the manuscript. JDB participated in the design, and participated in data collection. RL participated in the design of the study, and participated in data collection. EMK conceived of the study, participated in its design, and interpreted the data/analysis. MM participated in the conception of the study and its design, and interpreted the data/ analysis. PJS conceived of the study, participated in its design, and interpreted the data/analysis. JSZ conceived of the study, participated in its design, and performed statistical analysis, and interpreted the data. All authors approved and contributed to the writing of the final manuscript.

\section{Ethics approval and consent to participate}

All volunteers gave written informed consent.

The Ethics Committee of the Academic Medical Center Amsterdam, approved the study (ref. no. 2011_043\#C2011130).

The study was registered in the Dutch Trial Register no. 2976. http:// www.trialregister.nl/trialreg/admin/rctview.asp?TC=2976.

\section{Consent for publication}

Not Applicable.

\section{Competing interests}

The authors declare that they have no competing interests regarding the publication of this paper.

\section{Publisher's Note}

Springer Nature remains neutral with regard to jurisdictional claims in published maps and institutional affiliations.

\section{Author details}

${ }^{1}$ Department of Respiratory Medicine, Academic Medical Center, University of Amsterdam, Room F-5-260, Amsterdam, The Netherlands. ${ }^{2}$ Center for Experimental and Molecular Medicine (CEMM), Academic Medical Center, University of Amsterdam, Amsterdam, The Netherlands. ${ }^{3}$ Department of Experimental Immunology, Academic Medical Center, University of Amsterdam, Amsterdam, The Netherlands. ${ }^{4}$ Catalysis Engineering, Chemical Engineering, Technical University of Delft, Delft, The Netherlands. ${ }^{5}$ Department of Pharmacy, Academic Medical Center, University of Amsterdam, Amsterdam, The Netherlands. 'Department of Respiratory Medicine, Onze Lieve Vrouwe Gasthuis, Amsterdam, The Netherlands.

\section{Received: 24 October 2016 Accepted: 24 August 2017}

\section{Published online: 06 September 2017}

\section{References}

1. Atkinson RW, Kang S, Anderson HR, Mills IC, Walton HA. Epidemiological time series studies of PM2.5 and daily mortality and hospital admissions: a systematic review and meta-analysis. Thorax. 2014 Jul;69(7):660-5.

2. Lu F, Xu D, Cheng Y, Dong S, Guo C, Jiang X, et al. Systematic review and meta-analysis of the adverse health effects of ambient PM2.5 and PM10 pollution in the Chinese population. Environ Res. 2015 Jan;136:196-204.

3. Rom WN, Boushey $\mathrm{H}$, Caplan A. Experimental human exposure to air pollutants is essential to understand adverse health effects. Am J Respir Cell Mol Biol. 2013 Nov;49(5):691-6.

4. Kelly FJ, Fussell JC. Linking ambient particulate matter pollution effects with oxidative biology and immune responses. Ann N Y Acad Sci. 2015 Mar;1340:84-94

5. Patel MM, Chillrud SN, Deepti KC, Ross JM, Kinney PL. Traffic-related air pollutants and exhaled markers of airway inflammation and oxidative stress in new York City adolescents. Environ Res. 2013 Feb;121:71-8.

6. Kubesch NJ, de NA WD, Martinez D, Carrasco-Turigas G, Bouso L, et al. Respiratory and inflammatory responses to short-term exposure to trafficrelated air pollution with and without moderate physical activity. Occup Environ Med. 2015 Apr;72(4):284-93.

7. Viehmann A, Hertel S, Fuks K, Eisele L, Moebus S, Mohlenkamp S, et al, Long-term residential exposure to urban air pollution, and repeated measures of systemic blood markers of inflammation and coagulation. Occup Environ Med. 2015 Sep;72(9):656-63.

8. Franklin BA, Brook R, Arden PC III. Air pollution and cardiovascular disease. Curr Probl Cardiol. 2015 May;40(5):207-38.
9. Donaldson K, Brown D, Clouter A, Duffin R, MacNee W, Renwick L, et al. The pulmonary toxicology of ultrafine particles. J Aerosol Med. 2002;15(2):213-20.

10. Schulz H, Harder V, Ibald-Mulli A, Khandoga A, Koenig W, Krombach F, et al. Cardiovascular effects of fine and ultrafine particles. J Aerosol Med. 2005; 18(1):1-22.

11. Hussain S, Boland S, Baeza-Squiban A, Hamel R, Thomassen LC, Martens JA, et al. Oxidative stress and proinflammatory effects of carbon black and titanium dioxide nanoparticles: role of particle surface area and internalized amount. Toxicology. 2009 Jun 16;260(1-3):142-9.

12. Daigle CC, Chalupa DC, Gibb FR, Morrow PE, Oberdorster G, Utell MJ, et al. Ultrafine particle deposition in humans during rest and exercise. Inhal Toxicol. 2003 May;15(6):539-52.

13. Muller L, Riediker M, Wick P, Mohr M, Gehr P, Rothen-Rutishauser B. Oxidative stress and inflammation response after nanoparticle exposure: differences between human lung cell monocultures and an advanced three-dimensional model of the human epithelial airways. J R Soc Interface. 2010 Feb 6;7(Suppl 1):S27-40.

14. Rothen-Rutishauser B, Muhlfeld C, Blank F, Musso C, Gehr P. Translocation of particles and inflammatory responses after exposure to fine particles and nanoparticles in an epithelial airway model. Part Fibre Toxicol. 2007:4:9.

15. Saber AT, Jacobsen NR, Jackson P, Poulsen SS, Kyjovska ZO, Halappanavar S, et al. Particle-induced pulmonary acute phase response may be the causal link between particle inhalation and cardiovascular disease. Wiley Interdiscip Rev Nanomed Nanobiotechnol. 2014;6(6):517-31.

16. Moller W, Felten K, Sommerer K, Scheuch G, Meyer G, Meyer P, et al. Deposition, retention, and translocation of ultrafine particles from the central airways and lung periphery. Am J Respir Crit Care Med. 2008 Feb 15;177(4):426-32.

17. Shah AP, Pietropaoli AP, Frasier LM, Speers DM, Chalupa DC, Delehanty JM, et al. Effect of inhaled carbon ultrafine particles on reactive hyperemia in healthy human subjects. Environ Health Perspect. 2008 Mar;116(3):375-80.

18. Horie M, Yoshiura Y, Izumi H, Oyabu T, Tomonaga T, Okada T, et al. Comparison of the Pulmonary Oxidative Stress Caused by Intratracheal Instillation and Inhalation of $\mathrm{NiO}$ Nanoparticles when Equivalent Amounts of $\mathrm{NiO}$ Are Retained in the Lung. Antioxidants (Basel). 2016;5(1).

19. Nemmar A, Yuvaraju P, Beegam S, Yasin J, Dhaheri RA, Fahim MA, et al. In vitro platelet aggregation and oxidative stress caused by amorphous silica nanoparticles. Int J Physiol Pathophysiol Pharmacol. 2015;7(1):27-33.

20. Hoogerwerf JJ, de Vos AF, Bresser P, Van der Zee JS, Pater JM, de BA, et al. Lung inflammation induced by lipoteichoic acid or lipopolysaccharide in humans. Am J Respir Crit Care Med. 2008 Jul 1;178(1):34-41.

21. Julius $P$, Lommatzsch $M$, Kuepper $M$, Bratke K, Faehndrich S, Luttmann W, et al. Safety of segmental allergen challenge in human allergic asthma. J Allergy Clin Immunol. 2008 Mar;121(3):712-7.

22. Miller MR, Hankinson J, Brusasco V, Burgos F, Casaburi R, Coates A, et al. Standardisation of spirometry. Eur Respir J. 2005 Aug;26(2):319-38.

23. EMA. Guideline on requirements for First-In-Man clinical trials for potential high-risk medicinal products. 23-7-2007. Ref Type: Online Source.

24. Strak M, Steenhof M, Godri KJ, Gosens I, Mudway IS, Cassee FR, et al. Variation in characteristics of ambient particulate matter at eight locations in the Netherlands- the RAPTES project. Atmos Environ. 2011;45:4442-53.

25. Du Rand IA, Blaikley J, Booton R, Chaudhuri N, Gupta V, Khalid S, et al. British Thoracic Society guideline for diagnostic flexible bronchoscopy in adults: accredited by NICE. Thorax. 2013 Aug:68(Suppl 1):i1-i44.

26. Berger M, Kooyman PJ, Makkee M, Van der Zee JS, Sterk PJ, van DJ, et al. How to achieve safe, high-quality clinical studies with non-medicinal investigational products? A practical guideline by using intra-bronchial carbon nanoparticles as case study. Respir Res. 2016;17(1):102.

27. Jacobs L, Nawrot TS, de GB MR, Degraeuwe B, Bernard A, et al. Subclinical responses in healthy cyclists briefly exposed to traffic-related air pollution: an intervention study. Environ Health. 2010;9:64

28. Frampton MW, Stewart JC, Oberdorster G, Morrow PE, Chalupa D, Pietropaoli AP, et al. Inhalation of ultrafine particles alters blood leukocyte expression of adhesion molecules in humans. Environ Health Perspect. 2006 Jan;114(1):51-8.

29. Kager LM, de Boer JD, Bresser P, Van der Zee JS, Zeerleder S, Meijers JC, et al. Intrabronchial activated protein C enhances lipopolysaccharide-induced pulmonary responses. Eur Respir J. 2013 Jul;42(1):188-97.

30. Creutzenberg O, Bellmann B, Korolewitz R, Koch W, Mangelsdorf I, Tillmann $\mathrm{T}$, et al. Change in agglomeration status and toxicokinetic fate of various nanoparticles in vivo following lung exposure in rats. Inhal Toxicol. 2012 Oct;24(12):821-30. 
31. Husain M, Kyjovska ZO, Bourdon-Lacombe J, Saber AT, Jensen KA, Jacobsen $\mathrm{NR}$, et al. Carbon black nanoparticles induce biphasic gene expression changes associated with inflammatory responses in the lungs of C57BL/6 mice following a single intratracheal instillation. Toxicol Appl Pharmacol. 2015 Dec 15;289(3):573-88.

32. Gardner B, Ling F, Hopke PK, Frampton MW, Utell MJ, Zareba W, et al. Ambient fine particulate air pollution triggers ST-elevation myocardial infarction, but not non-ST elevation myocardial infarction: a case-crossover study. Part Fibre Toxicol. 2014;11:1.

33. Schreiber N, Strobele M, Kopf J, Hochscheid R, Kotte E, Weber P, et al. Lung alterations following single or multiple low-dose carbon black nanoparticle aspirations in mice. J Toxicol Environ Health A. 2013;76(24):1317-32.

34. Durga M, Nathiya S, Rajasekar A, Devasena T. Effects of ultrafine petrol exhaust particles on cytotoxicity, oxidative stress generation, DNA damage and inflammation in human A549 lung cells and murine RAW 264.7 macrophages. Environ Toxicol Pharmacol. 2014 Sep;38(2):518-30.

35. Voorhis M, Knopp S, Julliard W, Fechner JH, Zhang X, Schauer JJ, et al. Exposure to atmospheric particulate matter enhances Th17 polarization through the aryl hydrocarbon receptor. PLoS One. 2013;8(12):e82545.

36. Langrish JP, Bosson J, Unosson J, Muala A, Newby DE, Mills NL, et al. Cardiovascular effects of particulate air pollution exposure: time course and underlying mechanisms. J Intern Med. 2012 Sep;272(3):224-39.

37. Hatmi ZN, Saeid AK, Broumand MA, Khoshkar SN, Danesh ZF. Multiple inflammatory prognostic factors in acute coronary syndromes: a prospective inception cohort study. Acta Med Iran. 2010 Jan;48(1):51-7.

38. Sabatine MS, Morrow DA, Cannon CP, Murphy SA, Demopoulos LA DiBattiste PM, et al. Relationship between baseline white blood cell count and degree of coronary artery disease and mortality in patients with acute coronary syndromes: a TACTICS-TIMI 18 (treat angina with Aggrastat and determine cost of therapy with an invasive or conservative strategythrombolysis in myocardial infarction 18 trial)substudy. J Am Coll Cardiol. 2002 Nov 20;40(10):1761-8.

39. Tanaka M, Aoki Y, Takano H, Fujitani Y, Hirano S, Nakamura R, et al. Effects of exposure to nanoparticle-rich or -depleted diesel exhaust on allergic pathophysiology in the murine lung. J Toxicol Sci. 2013 Feb:38(1):35-48.

40. Geiser M, Stoeger T, Casaulta M, Chen S, Semmler-Behnke M, Bolle I, et al. Biokinetics of nanoparticles and susceptibility to particulate exposure in a murine model of cystic fibrosis. Part Fibre Toxicol. 2014;11:19.

41. Zhang R, Dai Y, Zhang X, Niu Y, Meng T, Li Y, et al. Reduced pulmonary function and increased pro-inflammatory cytokines in nanoscale carbon black-exposed workers. Part Fibre Toxicol. 2014;11:73.

\section{Submit your next manuscript to BioMed Central and we will help you at every step:}

- We accept pre-submission inquiries

- Our selector tool helps you to find the most relevant journal

- We provide round the clock customer support

- Convenient online submission

- Thorough peer review

- Inclusion in PubMed and all major indexing services

- Maximum visibility for your research

Submit your manuscript at wuw biomedcentral.com/submit

CBiomed Central 